\title{
Towards an ICF-based self-report questionnaire for people with skeletal dysplasia to study health, functioning, disability and accessibility
}

Heidi Anttila ${ }^{1 *} \mathbb{D}$, Susanna Tallqvist ${ }^{2}$, Minna Muñoz ${ }^{3}$, Sanna Leppäjoki-Tiistola ${ }^{4,5}$, Outi Mäkitie ${ }^{6,7}$ and Sinikka Hiekkala 3,5

\begin{abstract}
Background: Little is known about the spectrum of everyday challenges that people with skeletal dysplasia face because of their health and functioning. We aimed to identify factors related to health, functioning and disability in people with skeletal dysplasia, and their challenges with accessibility in order to form a self-reported questionnaire for national data collection. The comprehensive musculoskeletal post-acute core set of the International Classification of Functioning, Disability and Health (ICF) was used as a framework.
\end{abstract}

Methods: An iterative, participatory and qualitative process was used to formulate a questionnaire. Items were searched from Patient-Reported Outcomes Measurement Information System and from other self-report instruments, additional items were formulated using ICF linking rules. Expert panels from the target population assessed the face and content validity in thematic interviews.

Results: The questionnaire demonstrated its relevance, comprehensiveness and feasibility for people with skeletal dysplasia. The ICF linkages showed the contents' correspondence to the construct. Expert panels added 15 categories and one on chapter level to the core set and confirmed content validity. The final survey covers 86 ICF categories and 173 ICF-linked items that were grouped to 33 questions.

Conclusions: The content of the questionnaire proved to be sufficiently valid for people with skeletal dysplasia. It can be used to explore their health, functioning, disability and accessibility to develop care and rehabilitation policies, to plan services and to provide information to various parties involved.

Keywords: Functioning, Disability, Environmental factors, Self-report, Questionnaire design, Content validity, Skeletal dysplasia, Short stature, Rare disease

\footnotetext{
*Correspondence: heidi.anttila@thl.fi

${ }^{1}$ Public Health and Welfare Department, Knowledge Management

and Co-Creation Unit, Finnish Institute for Health and Welfare,

Mannerheimintie 166, 01270 Helsinki, Finland

Full list of author information is available at the end of the article
}

\begin{abstract}
Introduction
Individuals with short stature experience several challenges in the accessibility in society although they have the same rights as people with normal height [41]. Health and functioning play a major role in enabling them to participate in daily activities, social events and society. Short stature is a predominant feature in several rare conditions classified as skeletal dysplasia. These disorders
\end{abstract} permits use, sharing, adaptation, distribution and reproduction in any medium or format, as long as you give appropriate credit to the original author(s) and the source, provide a link to the Creative Commons licence, and indicate if changes were made. The images or other third party material in this article are included in the article's Creative Commons licence, unless indicated otherwise in a credit line to the material. If material is not included in the article's Creative Commons licence and your intended use is not permitted by statutory regulation or exceeds the permitted use, you will need to obtain permission directly from the copyright holder. To view a copy of this licence, visit http://creativecommons.org/licenses/by/4.0/. The Creative Commons Public Domain Dedication waiver (http://creativeco mmons.org/publicdomain/zero/1.0/) applies to the data made available in this article, unless otherwise stated in a credit line to the data. 
affect the musculoskeletal system already prenatally and during the years of growth. The affected children differ in height from their peers and the attained adult height is less than 140-150 cm. [24]).

There are numerous different medical reasons for short stature, including more than 400 hereditary diseases of the skeletal system (skeletal dysplasias), chromosomal aberrations, hormone deficiencies and developmental disorders [24]. Classification solely by categorical diagnosis does not provide sufficient information about the impact of the condition on individuals' lives and "lived experience". The few earlier small studies have reported conflicting results [35] on selected aspects of functioning in specific skeletal dysplasias, such as health-related quality of life [1, 42], pain and self-care, mobility and participation [18], as well as income, education and partnerships [15]. Planning of care, rehabilitation and social services, however, requires detailed and accurate knowledge about individual life situations. Recent legislative developments in Europe and United States and high public administration bodies support efforts to include patients' reports of health experience in order to engage in shared decision-making, prioritize the focus of treatment and services and to evaluate treatment outcomes $[5,10]$. Therefore, in health-related studies in people with short stature, it is of great importance to include assessment of functioning, disability and accessibility.

The World Health Organisation (WHO) has developed the International Classification for Functioning, Disability and Health (ICF), among others, for describing functioning in relation to health condition [46]. The ICF is part of the WHO's family of the international classifications, developed to provide a comprehensive and universally accepted framework to understand the lived experience of health in individuals as well as in populations. The concept of functioning is introduced explicitly in the biopsychosocial model that forms the ICF framework [28]. According to this model, the level of a person's individual functioning is the outcome of a dynamic and complex interaction between the health condition, body functions and structures (physiological functions and anatomical parts of the body system), activities (execution of a task) and participation (involvement in life situations), personal factors (features intrinsic to an individual) and environmental factors (physical, social and attitudinal environment), which can be facilitators or barriers. The interaction between these components is dynamic and bidirectional, changes in one component may influence one or more of the other components.

In addition to the framework, the ICF has over 1600 categories providing an exhaustive classification of an individual's functioning, suitable for all people. Core sets were made to help focus on the most important factors of certain health statuses [34]. The available 35 health-condition and context specific ICF core sets cover most burdensome health conditions [32], while the ICF Rehabilitation set (also called as Generic-30) is recommended for broad clinical and rehabilitation contexts [26] and the short ICF Generic-7 set to be used always [6]. Tools for assessment of functioning can be derived from core sets suitable for target population, validated and implemented to ensure that the ICF framework is applied [27, 33]. Though the ICF has been accepted in all WHO member states, it has been mostly applied in neurological, musculoskeletal and workrelated contexts [21]. We found no ICF-based tool for people with short stature due to skeletal dysplasia.

\section{Methods}

\section{Aim, design and setting}

In this study we aimed to formulate a self-report questionnaire using the ICF to study health, functioning, disability and accessibility in people with short stature due to skeletal dysplasia. The questionnaire was needed for a national study to explore the lived experience of functioning, disability and health of people with short stature, as well as their challenges concerning accessibility and equality, to guide in planning their health care and rehabilitation services on the national level. In our previous study [17] the questionnaire was applied to 80 people with skeletal dysplasia, and the scoring method and the results were described. In the present study the questionnaire's content validity was evaluated using the following research questions: Are all items relevant for the intended purpose of the questionnaire? Are all items relevant for people with skeletal dysplasia with respect to age, gender and disease characteristics? Do all items refer to relevant aspects of the construct to be measured?

\section{Target population}

We considered short stature, disproportion, deformities and joint restrictions to be the major features affecting functioning in skeletal dysplasias. The target population was specified as people with short stature due to one of the three most common skeletal dysplasias in Finland: diastrophic dysplasia, achondroplasia and cartilage-hair hypoplasia. Their common clinical features are musculoskeletal problems and severe short stature (Table 1). Diastrophic dysplasia is one of the most severe skeletal dysplasias with significant deformities and joint contractures while achondroplasia is the most common skeletal dysplasia world-wide. People with short stature were recruited by announcements and personal contacts. 
Table 1 Characteristics of the three most common congenital skeletal dysplasias in Finland

\begin{tabular}{|c|c|}
\hline Health condition & Clinical features \\
\hline \multirow[t]{5}{*}{ Diastrophic dysplasia (autosomal recessive inheritance) OMIM \#222,600 } & $\begin{array}{l}\text { Disproportionate short stature with short arms and legs, scoliosis, joint } \\
\text { deformities and contractures, and foot deformities }\end{array}$ \\
\hline & Normal mental development and life expectancy \\
\hline & $\begin{array}{l}\text { Progressive degenerative changes of the articular cartilage and severe joint } \\
\text { deformities often require hip and knee arthroplasties at an early age }\end{array}$ \\
\hline & Adult height $130-140 \mathrm{~cm}$ \\
\hline & More common in Finland than in any other country \\
\hline \multirow[t]{5}{*}{ Achondroplasia (autosomal dominant inheritance) OMIM \#100,800 } & $\begin{array}{l}\text { Characteristic appearance of disproportionate short stature with short } \\
\text { limbs and long spine }\end{array}$ \\
\hline & $\begin{array}{l}\text { Other complications include e.g. delayed motor milestones and leg deform- } \\
\text { ities in childhood; spinal stenosis, pain, and complications with aging }\end{array}$ \\
\hline & $\begin{array}{l}\text { Normal cognition and overall physical development and are productive } \\
\text { and independent adults }\end{array}$ \\
\hline & Adult height $120-135 \mathrm{~cm}$ \\
\hline & The most common skeletal dysplasia worldwide \\
\hline \multirow[t]{5}{*}{$\begin{array}{l}\text { Cartilage-hair hypoplasia (autosomal recessive inheritance) OMIM } \\
\text { \#250,250 }\end{array}$} & $\begin{array}{l}\text { A highly pleiotropic disorder with many features involving various extra- } \\
\text { skeletal organ systems }\end{array}$ \\
\hline & $\begin{array}{l}\text { Disproportionate stature with short limbs, normal joint function, sparse hair, } \\
\text { variable immunodeficiency and predisposition to malignancies }\end{array}$ \\
\hline & Normal intelligence and developmental milestones \\
\hline & Adult height $104-149 \mathrm{~cm}$ \\
\hline & More common in Finland than in any other country \\
\hline
\end{tabular}

\section{Construct}

The construct to be evaluated was defined as health, functioning, disability and accessibility. The term "health" was defined as diagnosis, as described in the ICD-10 (International Statistical Classification of Diseases and Related Health Problems) [47] or as health problems described by ICF body functions (BF). The latter terms were defined using the ICF as a framework. "Functioning" and "disability" were described by using categories from the ICF body functions (BF), body structures (BS), activities and participation (A\&P) domains and "accessibility" by facilitators or barriers in the environmental factors (EF) domain. Because the skeletal dysplasia can be classified to rare musculoskeletal diseases, we chose the comprehensive musculoskeletal post-acute ICF core set as an initial set of "what to measure" [31]. This core set includes 70 ICF categories (23 in BF, 7 in BS, $22 \mathrm{~A} \& \mathrm{P}$, and 18 in EF). It covers all 7 categories in the ICF Generic set and 36 of the 42 categories of the ICF Rehabilitation set with environmental factors.

\section{Questionnaire development}

The questionnaire development (Fig. 1) was carried out between February and August 2016. The research group (authors) has wide experience of medical, health, and social sciences and the target group. To ensure participatory approach throughout the study, an expert panel $(n=4)$, representing different skeletal dysplasia diagnoses (Table 1), was formed to assess face validity, feasibility and acceptance of the survey.

Requirements for items were that an item (a question or a phrase) should be relevant and acceptable for subjects with short stature due to skeletal dysplasia, capture the person's subjective valuation of symptoms or functioning i.e. patient reported outcome (PRO), be in 1st person, be simple to understand and easy to respond, be publicly available, and should be able to be linked to one of the preselected ICF categories using the updated ICF linking rules [7]. A requirement for the final questionnaire was that completion time should not be too long and the survey should not include overlapping questions. Thus, the number of items should be adjusted so as to reach completion time of 15-20 min.

We sought items from validated self-report instruments. The Patient-Reported Outcomes Measurement Information System (PROMIS ${ }^{\circledR}$ ) item banks have been developed by comprehensive literature searches of existing measures, using appropriate cognitive testing and contemporary psychometric methods [4]. The PROMIS has demonstrated rapid, accurate measurement and clinical validity across a range of chronic conditions [9]. This system provides extensively developed self-report items for assessing physical, mental, and social health in 25 item banks and short-forms derived from these banks. 


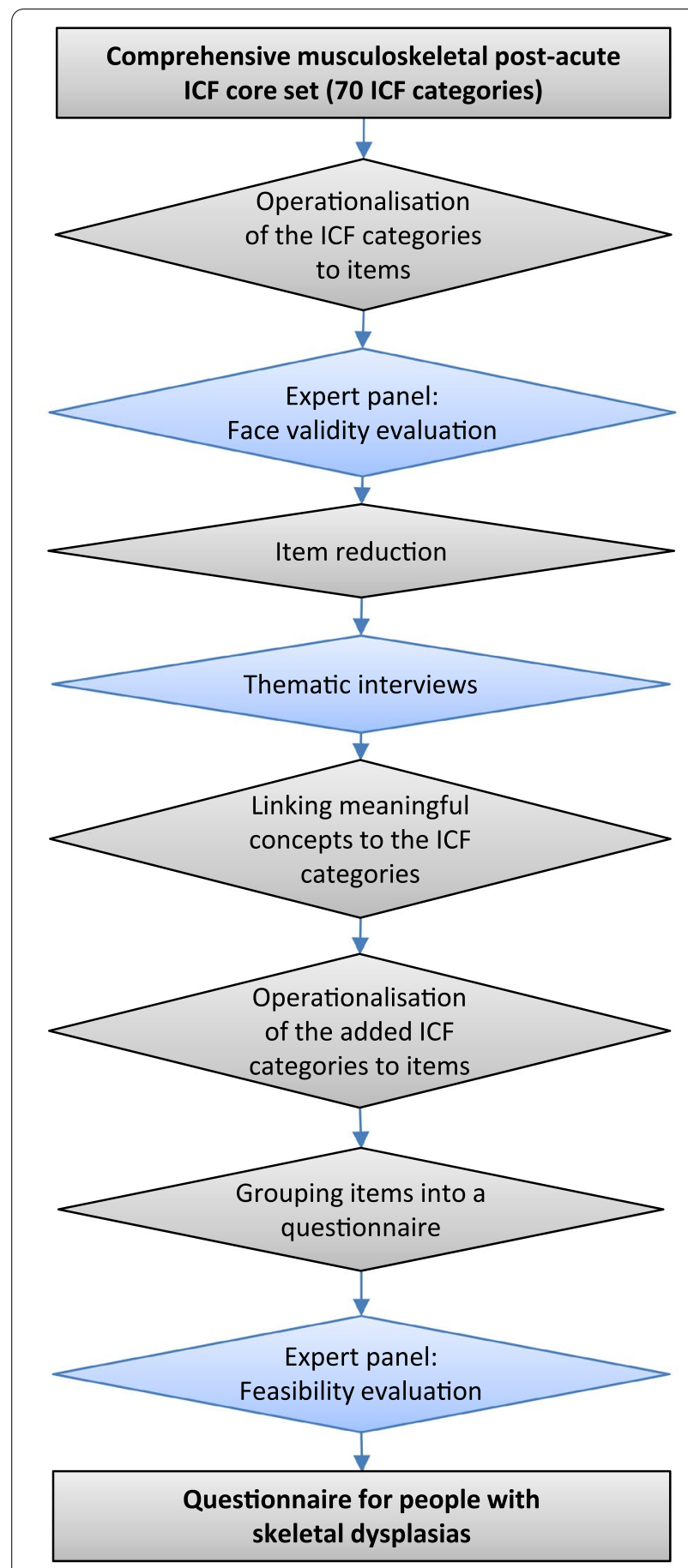

Fig. 1 The process of the questionnaire development for people with skeletal dysplasias

The items are short and easy to understand [11], have short recall time (7 days) except physical function items [8], and five-point answering options [25]. Tucker et al. [38] demonstrated harmonization and synergy between the PROMIS and the ICF conceptual frameworks. The mapping of 1007 items from PROMIS adult item banks to ICF code descriptors shows that the PROMIS items provide a basis for majority of concepts in the ICF BF and A\&P categories [39].

To identify items for ICF EF categories we utilized several sources. Recent reviews [20, 29] identified selfreport measures on how environmental barriers or facilitators impact participation for people with disabilities: Craig Hospital Inventory of Environmental Factors (CHIEF) [44] and Measure of the Quality of the Environment (MQE) [14]. The 25 CHIEF items ask "In the past 12 months, how often has [an EF] been a problem for you", and then "when this problem occurs has it been a big problem or a little problem". The MQE asks "While taking into consideration your abilities and personal limits, indicate to what extent the following situations or factors generally influence your daily life" for $109 \mathrm{EF}$ listed. National Finsote Survey covers some EF and is implemented throughout Finland to monitor the welfare and health of their residents [13]. As the CHIEF and MQE were not available in Finnish, we utilized their items as a basis to formulate new items. Lastly, if no item for the ICF categories could be identified from existing sources, the research group phrased a new item using the ICF definition and existing PROMIS item formats (stems, responses, tense and person [11].

\section{Assessment of face and content validity}

The expert panel was asked to do an overall view of the items (i.e. face validity) [12] and to accept "suitable" items, reject "redundant" items and provide comments for each item. Thereafter, item reduction aimed to come down to a reasonably low number of items to reach the preset completion time limit. Decision rules for keeping items were: (1) all of the four persons appraised the item as relevant and, (2) the item was in the PROMIS short form, as these items have best discriminative power [30].

We then searched target group input to assess whether the content of the questionnaire corresponds with the construct and its' relevance and comprehensiveness (i.e. content validation) [37]. This was done by structured, thematic interviews to understand how people with short stature experience functioning and accessibility and equality, and their review of the draft questionnaire. Fourteen signed informed consent ( 2 men, 9 women and 3 children aged 9-12 years with their parents), representing all three diagnoses and geographically different areas in Finland. Themes in the interview were functioning, accessibility and equality. The participants could tell about the above-mentioned themes in a preferable order. If needed, these themes were clarified to the participants by questions that were description objects from the ICF framework. In the end of interview the interviewer gave 
the participants the draft questionnaire and asked for its understandability and relevance. Thereafter, the participants were asked to accept or delete items, and provide comments, if needed, for each item.

The interviews lasted from $46 \mathrm{~min}$ to $1 \mathrm{~h}$ and $26 \mathrm{~min}$. Exact transcriptions of the thematic interviews were performed. The analysis was first based on the data and then linked to the theory i.e. the ICF framework [23, 40]. From the transcriptions we identified meaningful concepts about functioning (linking units) and mapped them to the ICF using the ICF linking rules [7]. The resulting ICF categories were compared to the 70 categories of comprehensive musculoskeletal post-acute core set.

\section{Results}

Relevance of the items for the questionnaire's planned use From the available item banks and questionnaires, we identified altogether 522 possible relevant items for a national questionnaire. Altogether, these items covered 37 categories of the chosen ICF core set (0 BS, 5 BF, 19 A\&P, $13 \mathrm{EF})$. There were 452 possible PROMIS items for 28 core set categories. The number of items per category varied from 1 to 108, for example, 108 items for energy and drive functions (b130), 18 for fine hand use (d440), and only one for transferring oneself (d420). The PROMIS covered 19 of the $22 \mathrm{~A} \& \mathrm{P}$ and 5 of the $23 \mathrm{BF}$ categories. Moreover, from the PROMIS we could identify a few items for EF, but on chapter level (e3, e4) only, as in those items one cannot say who gives support or whose attitude is in question. However, we accepted them to cover the ICF categories e355 and e410, e430, e440, respectively.

From the Finsote survey we identified two items about social life and 26 services. These items were modified to address 1 st person, and we added transportation services. From CHIEF and MQE we identified 25 items that were used as basis for item development, covering 10 of the 18 EF categories. The remaining EF categories and the many BF categories, not covered by any available items, were operationalized to items based on the ICF category definition. The EF items asked about accessibility at home and in other buildings and public places, as well as attitudes. The BF items inherently ask about health conditions or functions. The core set categories for weight (b530) was considered as a background variable, to which we added items outside the core set about age, height, cordage, gender, and life situation. The 7 BS categories were regarded non-relevant as self-report items, as these structural impairments were covered in the diagnoses (see Table 1) and were thus not operationalized as single items.
Relevance of the items for people with skeletal dysplasia The initial ICF core set related list included 531 items, most accepted by the expert panel as having good face validity. After item reduction, 161 items were kept and grouped to 117 questions in a draft questionnaire. Based on the comments from thematic interviews, 31 items were discarded, 9 modified and 8 added. The results from the thematic interviews brought more qualitative insight of the functioning, disability and accessibility experience by people with skeletal dysplasia. The themes originating from content analysis comprising of nine classes could be linked to all ICF domains: daily barriers (ICF BF and BS); work and leisure time, challenges in mobility and daily activities (ICF A\&P); facilitators for mobility and activities, social support, attitudinal environment, services, physical environment as a barrier or facilitator (ICF EF); and attitude towards oneself (ICF personal factors). The qualitative results are published elsewhere [16]. For the questionnaire development, the transcriptions provided details of the functioning, disability and accessibility changes that these people meet in their everyday life. In the transcriptions, there were 46 subcategories regarding functioning and environmental factors. Their linkages into the ICF categories are shown in Table 2. The linking confirmed the selection of several core set categories and yielded additional categories.

Based on the content validation, no core set category was deleted, but we added 15 second level ICF categories (9 A\&P and $6 \mathrm{EF}$ ), which were not included in the comprehensive musculoskeletal post-acute ICF core set. Moreover, the body structures that were first considered only as diagnoses were added at chapter level (s7). To operationalize the new categories, we added 33 items: 11 from PROMIS and 22 newly formulated items, including the three items for BS. Additional file 1 provides an overview of the number of items and their sources for each ICF category of the comprehensive post-acute musculoskeletal core set and the additional categories.

\section{Feasibility of the questionnaire}

A questionnaire was formulated, using the Webropol software. As the items could be grouped by similar answering options, the items did not follow the order of the ICF categories. Instead, the items were grouped to 32 questions under 10 lay language titles: sociodemographic factors; health and body functions; home, assistive products and vehicles; mobility; daily activities; mental welfare; pain; social relationships; work and leisure time; and social and health services. The expert panel tested the feasibility of the questionnaire and provided qualitative insights on fluency, understandability of the newly formulated items, as well 
Table 2 Meaningful concepts from interviewed people with skeletal dysplasias $(n=14)$ linked to the ICF categories

\begin{tabular}{|c|c|c|c|c|}
\hline Count & $\begin{array}{l}\text { Meaningful concepts on functioning or } \\
\text { accessibility }\end{array}$ & ICF code & ICF title & Decision \\
\hline 1 & Mental functioning & b130* & Energy and drive functions $(\mathrm{G})$ & Keep \\
\hline 2 & Sleeping & b134* & Sleep functions & Keep \\
\hline 3 & Pain & b280* & Pain (G) & Keep \\
\hline 4 & Allergies, infections & b435* & Immunological system functions & Keep \\
\hline 5 & Stiff joints & b710* & Mobility of joint functions & Keep \\
\hline 6 & Loose joints & b715* & Stability of joint functions & Keep \\
\hline 7 & Muscle strength & b730* & Muscle power functions & Keep \\
\hline 8 & Significance of a skill & d155* & Acquiring skills & Keep \\
\hline 9 & $\begin{array}{l}\text { Basic movements (turning oneself, getting up sitting } \\
\text { from lying, getting lying down on stomach, mov- } \\
\text { ing on ones buttock) }\end{array}$ & $d 410^{*}$ & Changing basic body position & Keep \\
\hline 10 & Using hands & $d 445^{*}$ & Hand and arm use & Keep \\
\hline 11 & Walking & $d 450^{*}$ & Walking (G) & Keep \\
\hline 12 & Running, climbing stairs & $\mathrm{d} 455$ & Moving around & Add \\
\hline 13 & Moving with public vehicles & $d 470$ & Using transportation & Add \\
\hline 14 & Personal hygiene, taking care of beauty & d520* & Caring for body parts & Keep \\
\hline 15 & Toileting, peeing and cannot wipe oneself & d530* & Toileting & Keep \\
\hline 16 & Dressing & d540* & Dressing & Keep \\
\hline 17 & Eating & d550* & Eating & Keep \\
\hline 18 & Difficulty of accessing services & d620 & Acquisition of goods and services & Add \\
\hline 19 & Preparing meals & d630 & Preparing meals & Add \\
\hline 20 & Doing housework e.g. washing clothes & d640 & Doing housework & Add \\
\hline 21 & Friends & $d 750$ & Informal social relationships & Add \\
\hline 22 & Work as a resource, doing work, having a career & d850 & Remunerative employment & Add \\
\hline 23 & $\begin{array}{l}\text { Hobbies (sports, games, circus, playing music, mov- } \\
\text { ies etc.) }\end{array}$ & d920 & Recreation and leisure & Add \\
\hline 24 & Experiencing oneself as a person with disability & d940 & Human rights & Add \\
\hline 25 & Small assistive technologies, special shoes & e115* & $\begin{array}{l}\text { Products and technology for personal use in daily } \\
\text { living }\end{array}$ & Keep \\
\hline 26 & $\begin{array}{l}\text { Assistive technologies for moving (car, electric } \\
\text { wheelchair or scooter) }\end{array}$ & e120* & $\begin{array}{l}\text { Products and technology for personal indoor and } \\
\text { outdoor mobility and transportation }\end{array}$ & Keep, but consider car \\
\hline 27 & Public vehicles & e1200 & $\begin{array}{l}\text { General products and technology for personal } \\
\text { indoor and outdoor mobility and transportation }\end{array}$ & Consider in e575 \\
\hline 28 & Changes to a car & e1201 & $\begin{array}{l}\text { Assistive products and technology for personal } \\
\text { indoor and outdoor mobility and transportation }\end{array}$ & Consider in e120 \\
\hline 29 & $\begin{array}{l}\text { Accessibility at public areas (study places, bank } \\
\text { automates, banks, shops, high desks, stairs, heavy } \\
\text { doors) }\end{array}$ & e150* & $\begin{array}{l}\text { Design, construction and building products and } \\
\text { technology of buildings for public use }\end{array}$ & Keep \\
\hline 30 & $\begin{array}{l}\text { Accessibility at home, changes to one's apart- } \\
\text { ment (socles, additional taps, heightened floor at } \\
\text { balcony, handles and grips, lowered washbasin, } \\
\text { power sockets, personal bath chair and furniture) }\end{array}$ & e155 & $\begin{array}{l}\text { Design, construction and building products and } \\
\text { technology of buildings for private use }\end{array}$ & Add \\
\hline 31 & $\begin{array}{l}\text { Accessibility at home entrance (lowered door han- } \\
\text { dles, electric lock, door pumps) }\end{array}$ & e1550 & $\begin{array}{l}\text { Design, construction and building products and } \\
\text { technology for entering and exiting of buildings } \\
\text { for private use }\end{array}$ & Consider in e155 \\
\hline 32 & Seasonal changes & e245 & Time-related changes & Add \\
\hline 33 & Support from family & $\mathrm{e} 310^{*}$ & Immediate family & Keep \\
\hline 34 & Support from friends and peers & e320* & Friends & Keep \\
\hline 35 & Support from personal assistant & $\mathrm{e} 340^{*}$ & Personal care providers and personal assistants & Keep \\
\hline 36 & Other people offer help without asking & e345 & Strangers & Add \\
\hline 37 & Attitudes in public services & e445 & Individual attitudes of strangers & Add \\
\hline 38 & Attitudes of health workers & $\mathrm{e} 450^{*}$ & Individual attitudes of health professionals & Keep \\
\hline
\end{tabular}


Table 2 (continued)

\begin{tabular}{|c|c|c|c|c|}
\hline Count & $\begin{array}{l}\text { Meaningful concepts on functioning or } \\
\text { accessibility }\end{array}$ & ICF code & ICF title & Decision \\
\hline 39 & Inequal access to services & e455 & Individual attitudes of other professionals & Add \\
\hline 40 & Other people's attitudes, discrimination & e460 & Societal attitudes & Add \\
\hline 41 & Public transportation services & e540 & Transportation services, systems and policies & Consider in e575 \\
\hline 42 & $\begin{array}{l}\text { Support from society (disability services and } \\
\text { benefits) }\end{array}$ & e575 & General social support services, systems and policies & Keep \\
\hline 43 & $\begin{array}{l}\text { Access to assistive products and transportation } \\
\text { services }\end{array}$ & e580* & Health services, systems and policies & Keep \\
\hline 44 & Other challenges (lymphatic drainage in the brain) & s110 & Structure of brain & Not include \\
\hline 45 & Joint detrition, bone fractures, accidents & s7 & Structures related to movements & Add \\
\hline 46 & Bone displacements (correction surgery) & s770 & $\begin{array}{l}\text { Additional musculoskeletal structures related to } \\
\text { movement }\end{array}$ & Consider in s7 \\
\hline
\end{tabular}

* Category belongs to the comprehensive musculoskeletal ICF core set

as ordering of items and suitability of item grouping. Changes were implemented, largest change was splitting one item for $\mathrm{d} 470$ into two i.e. transportation with and without luggage. One open question was added. The questionnaire was proof-read and finalized with 34 questions, consisting of 173 ICF-linked items (Additional file 1) and 6 sociodemographic items (contact information, age, length, cordage, gender, and life situation), and one open question. All the four individuals with skeletal dysplasia accepted the final questionnaire and completed it. The completion time was 15-20 min.

\section{Correspondence to the construct}

The use of the ICF linking rules demonstrated, to what ICF domains and categories the items in the questionnaire belong. All the additional items address health, functioning or accessibility and thus belong to the construct. Thus, the final number of ICF categories was 86 , comprising of 25 categories describing the construct of

Table 3 The correspondence of the questionnaire to the ICF domains, the identified themes and the construct

\begin{tabular}{|c|c|c|c|c|}
\hline $\begin{array}{l}\text { Titles (number of questions) } \\
\text { in the questionnaire }\end{array}$ & $\begin{array}{l}\text { Number of } \\
\text { ICF-linked items } \\
(n=173)\end{array}$ & $\begin{array}{l}\text { ICF domains in the } \\
\text { questionnaire (number of } \\
\text { categories, } n=86 \text { ) }\end{array}$ & $\begin{array}{l}\text { Themes identified in content } \\
\text { analysis from thematic } \\
\text { interviews }\end{array}$ & Construct \\
\hline 1. Background information (5)* & 2 & $\begin{array}{l}\text { Body structures (7), Body func- } \\
\text { tions (1) }\end{array}$ & & Health \\
\hline 2. Health and body functions (6) & 42 & $\begin{array}{l}\text { Body structures (1), Body func- } \\
\text { tions (16) }\end{array}$ & Daily barriers (ICF BF and BS) & Health \\
\hline $\begin{array}{l}\text { 3. Home, assistive products and } \\
\text { vehicles (4) }\end{array}$ & 5 & Environmental factors (2) & $\begin{array}{l}\text { Physical environment as a bar- } \\
\text { rier or facilitator (ICF EF) }\end{array}$ & Accessibility \\
\hline 4. Mobility (3) & 30 & $\begin{array}{l}\text { Body functions (2) activities and } \\
\text { participation (10), environ- } \\
\text { mental factors (3) }\end{array}$ & $\begin{array}{l}\text { Challenges in mobility and } \\
\text { daily activities (ICF A\&P), } \\
\text { Facilitators for mobility and } \\
\text { activities (EF) }\end{array}$ & $\begin{array}{l}\text { Functioning and disability, } \\
\text { accessibility }\end{array}$ \\
\hline 5. Daily activities (2) & 25 & $\begin{array}{l}\text { Activities and participation (14), } \\
\text { environmental factors (3) }\end{array}$ & $\begin{array}{l}\text { Challenges in mobility and } \\
\text { daily activities (ICF A\&P) }\end{array}$ & $\begin{array}{l}\text { Functioning and disability, } \\
\text { accessibility }\end{array}$ \\
\hline 6. Mental welfare (3) & 13 & $\begin{array}{l}\text { Body functions (3), activities } \\
\text { and participation (3) }\end{array}$ & $\begin{array}{l}\text { Attitude towards oneself (ICF } \\
\text { personal factors) }\end{array}$ & Functioning and disability, \\
\hline 7. Pain (3) & 4 & Body functions (1) & & Functioning and disability \\
\hline 8. Social relationships (2) & 16 & $\begin{array}{l}\text { Activities and participation (3), } \\
\text { environmental factors (9) }\end{array}$ & $\begin{array}{l}\text { Social support (EF), attitudinal } \\
\text { environment (EF) }\end{array}$ & Functioning and disability \\
\hline 9. Work and leisure time (3) & 6 & $\begin{array}{l}\text { Activities and participation (1), } \\
\text { environmental factors (1) }\end{array}$ & Work and leisure time (A\&P) & $\begin{array}{l}\text { Functioning and disability, } \\
\text { accessibility }\end{array}$ \\
\hline $\begin{array}{l}\text { 10. Social and health services } \\
\text { (2) }\end{array}$ & 30 & Environmental factors (6) & Services (EF) & Accessibility \\
\hline
\end{tabular}

* Only two of the background items were ICF-linked (weight and diagnosis) 
health (8 BS and $17 \mathrm{BF}$ ), 35 functioning and disability (6 BF, 31 A\&P), and 24 accessibility (ICF EF). Table 3 illustrates the correspondence of the lay titles and items in the final questionnaire to the ICF domains, the themes identified from thematic interviews, and the construct terms.

\section{Discussion}

In the present study, we describe how to operationalize an ICF core set to capture lived experience of persons with a rare disease, such as short stature due to skeletal dysplasia. Items were searched from state-of-art item banks, such as the PROMIS and other widely used questionnaires or surveys. Many items, particularly on EF had to be newly formulated in the Finnish language. People with skeletal dysplasia were consulted in all phases. As a result, a questionnaire was compiled in an iterative, participatory and qualitative process that demonstrated its preliminary relevance and feasibility for people with skeletal dysplasia.

Content validation is the most important step in questionnaire development [37]. We gave information about construct and situation for which the questionnaire was developed. The expert panel of individuals with skeletal dysplasia assessed the face validity of the questionnaire after which experts from the target population assessed whether the questionnaire content was relevant and comprehensive in a qualitative study. The correspondence to the construct was assessed by linking the items to the ICF categories.

Previously, the Quality of Life in Short Stature Youth instrument have been developed for people with short stature and used to study their health-related quality of life, including physical, social and emotional domains clinical contexts $[3,19]$. The instrument targeted children and adolescents and their parents. In this study, however, we developed a survey for adults to be used in national context with wider content as guided by the comprehensive musculoskeletal post-acute ICF core set and the thematic interviews.

This study provides further evidence for the ICF core sets' applicability in survey design (see also [36]) and the use of the ICF framework for content validation of a questionnaire (see also [43]). The selected ICF core set worked well as a basis for the survey as well as for the interview themes. Meanwhile, the WHO has published a supplementary section for functioning assessment in the ICD-11, to enable joint use of ICF with the ICD [45]. This chapter includes 47 functioning domains of high explanatory power. One benefit of having codes for each questionnaire item is to enable comparison. Our ICFbased questionnaire for people with short stature covers 29 of the 47 functioning domains of the ICD-11, but the
ICD-11 lacks the further 58 categories that were meaningful for people with short stature.

There were many reasons for choosing PROMIS items to operationalize the ICF categories on functioning. The PROMIS tools are being adopted to assess a broad range of disease outcomes worldwide, as they enable a common metric for tracking outcomes across providers and medical systems [2]. By applying PROMIS items, the questionnaire has taken one step further for more standardized assessment of functioning across conditions. The used health domains of PROMIS measures included physical function, pain, fatigue, sleep disturbance, self-efficacy, satisfaction with social roles and activities, ability to participate in social roles and activities, and social support. The PROMIS short forms were translated into Finnish in a collaborative FinSCI study [36].

The PROMIS item banks provided both too many and too few items. To overcome excess of items for the same category, short forms of these item banks were considered, however, only single items could be utilized to reduce patient burden. Future studies should investigate the possibility to apply item banks via computer adapted testing (CAT). This would allow calculating results per health domain, and at the same time with reduced patient burden provide more exact results than the short forms [4]. Also, many new items needed to be formulated, particularly for BF and EF not available in PROMIS item banks. The health condition items covered BF well, but item development for EF was more cumbersome. The CHIEF and MQE were not available in Finnish, so we could only use them at issue level to help item formulation in Finnish.

Normal accessibility criteria are often of no use for people with short stature. Accessibility is not only question of reachability, but a matter of being able to use buildings and traffic systems, work or enjoy leisure time with or without technical aids, as other people. In addition to the existing items, the target group participants were able to inform in the interviews what and how to formulate items to ask about these important environmental factors. Moreover, representatives of the target group were important and active participants throughout the study; in study design, selection of the content, reviewing the analyses and confirming the results. They ensured that the final questionnaire became feasible and non-burdensome. All the new items were commented and accepted by the group of four individuals with short stature, however, these items should go under more rigorous cognitive testing in the future.

The study included a number of qualitative methods that were used iteratively and ensured that voices of people with short stature were heard. The thematic interviews provided important means to identify 
what is important about functioning and accessibility to people with short stature and to confirm the relevance of the survey content. The analyses were first conducted based on the findings, and then linked to the ICF. The linking proved to be clear, and there were no big discrepancies between the researchers. This revealed that the preselected categories from the comprehensive musculoskeletal post-acute ICF core set proved to be useful, but did not cover all relevant aspects. Fourteen new categories were added based on personal perspectives identified in qualitative interviews. The themes and issues remained the same across the participants, thus we consider that saturation was reached: new interviews did not reveal substantially new information. Studies have shown that saturation point can be reached in qualitative studies with 11 participants [22] and our study included 14 participants.

This study has number of limitations. The questionnaire was designed and piloted with a small number of adults with skeletal dysplasia. We consider this justified because of the rarity of the conditions. Considering the large number and variable presentation of skeletal dysplasias, the inclusion of only three skeletal dysplasias may be a limitation of study. However, we considered short stature, disproportion, deformities and limited joint function to be the major features affecting functioning of adults with skeletal dysplasia. The included three skeletal dysplasias all present with severe disproportionate short stature. Diastrophic dysplasia is one of the most severe skeletal dysplasias with significant deformities and joint contractures. Achondroplasia is the most common skeletal dysplasia world-wide and it was important to include this disorder in our study.

The questionnaire might be suitable for other skeletal dysplasia, but as the number of individuals in these populations is even smaller, international collaboration would be needed for greater samples to test the questionnaires suitability for all skeletal dysplasias. Nevertheless, we aimed for comprehensive evaluation of functioning based on an internationally accepted ICF core set for wider applicability. The musculoskeletal post-acute ICF core set was used as the main challenges relate to skeletal condition. The questions were not based on the diagnosis, the form of disability nor the stature of the person. They focus on the challenges and consequences on functioning that may arise in daily life for a person with disability. Moreover, there are many issues specifically in childhood, but were not included in the questionnaire, as it was designed for adults only.

\section{Conclusions}

We developed a self-report questionnaire based on the musculoskeletal post-acute ICF core set with 15 additional ICF categories and one on chapter level to study health, functioning, disability and accessibility in people with skeletal dysplasia. The content validity was well accepted by the target group: the content was comprehensive, the operationalized items sufficiently relevant and measured the construct, and the questionnaire was feasible to use. We are confident that the developed ICFbased questionnaire can produce relevant data on life situations in people affected by skeletal dysplasia and short stature. The obtained data can be utilized to better understand their health, functioning, disability and challenges with accessibility in order to develop care and rehabilitation policies, and to plan services.

\section{Abbreviations}

A\&P: Activity and participation; BF: Body functions; BS: Body structures; CHIEF: Craig hospital inventory of environmental factors; EF: Environmental factors; ICD-10: International statistical classification of diseases and related health problems 10th revision; ICD-11: International classification of diseases for mortality and morbidity statistics 11 th revision; ICF: International classification for functioning, disability and health; MQE: Measure of the quality of the environment; PROMIS: Patient-reported outcomes measurement information system; WHO: World health organization.

\section{Supplementary Information}

The online version contains supplementary material available at https://doi. org/10.1186/s13023-021-01857-7.

Additional file 1. Number of items and item sources of the questionnaire for people with skeletal dysplasias.

\section{Acknowledgements}

We thank architect Kirsti Pesola for drafting accessibility items, Ad. Prof Antti Teittinen for help in finalizing the questionnaire and MSc student Hanna Hyvönen for harmonizing numbers and commenting the final manuscript. We are grateful to the individuals with short stature who participated in the expert panel and the qualitative study.

\section{Authors' contributions}

$\mathrm{HA}$ and $\mathrm{SH}$ drafted the study protocol, all other authors were involved with planning, data analysis and interpretation. SL-T was responsible for getting participants to interviews and communicating through the Lyhytkasvuiset-Kortväxta association. ST and MM carried out the interviews and their analysis, HA and SH linked the meaningful concepts to the ICF. SH, HA and $\mathrm{KP}$ formulated $\mathrm{EF}$ items, $\mathrm{SH}$ and $\mathrm{OM}$ formulated $\mathrm{BF}$ and $\mathrm{BS}$ items. HA wrote the manuscript, all the other authors critically commented and approved the manuscript.

\section{Funding}

This research was funded by the Ministry of Social Affairs and Health (201610100), by Helsinki University Hospital (HUS512/13/01/00/2014, HUS461/13/01/00/2015, and HUS1048/2017), Academy of Finland (318137), Novo Nordisk Foundation (NNF180C0034982), and by the organizations of the research group.

\section{Availability of data and materials}

The anonymous data qualitative data from the thematic interviews in Finnish is not publicly available but reasonable requests to the access of data will be 
considered by the corresponding author. All other data generated or analysed during this study are included in this published article and its supplementary information files. The comprehensive musculoskeletal ICF core set is available at https://www.icf-research-branch.org/icf-core-sets. The PROMIS@ items that were used in this study are available in English and Spanish from Health Measures service www.healthmeasures.net, but restrictions apply to the availability of other languages of these items, which were used under license for the current study, and so are not publicly available. The items are however available from the authors upon reasonable request and with permission of PROMIS Health Organization. The questionnaire is in Finnish and is available from the corresponding author on reasonable request.

\section{Declaration}

\section{Ethics approval and consent to participate}

Ethics approval was obtained from the University of Helsinki Ethical Review Board in the Humanities and Social and Behavioral Sciences: Statement $1 / 2016,13.1 .2016$. A written informed consent was obtained from the study participants before the start of the study. Anonymized data was used for analysis and publication. Hence, the study has been performed in accordance with the ethical standard laid down in the 1964 Declaration of Helsinki and its later amendments.

\section{Consent for publication}

A written informed consent was signed by the study participants in the qualitative study.

\section{Competing interests}

The authors declare that they have no competing interests.

\section{Author details}

${ }^{1}$ Public Health and Welfare Department, Knowledge Management and Co-Creation Unit, Finnish Institute for Health and Welfare, Mannerheimintie 166, 01270 Helsinki, Finland. ${ }^{2}$ University of Helsinki, Yliopistonkatu 3, 00014 Helsinki, Finland. ${ }^{3}$ Validia Ltd, Validia Rehabilitation, Nordenskiöldinkatu 18 B, 00250 Helsinki, Finland. ${ }^{4}$ Lyhytkasvuiset - Kortväxta ry (Finnish Association for People with Restricted Growth and for Their Families), PO Box 14, 02601 Espoo, Finland. ${ }^{5}$ Finnish Association of People With Physical Disabilities, Mannerheimintie 107, 00280 Helsinki, Finland. ${ }^{6}$ Children's Hospital, University of Helsinki and Helsinki University Hospital, P.O. Box 63, 00014 Helsinki, Finland.

${ }^{7}$ Folkhälsan Institute of Genetics, Helsinki, Finland.

Received: 6 May 2020 Accepted: 6 May 2021

Published online: 22 May 2021

\section{References}

1. Apajasalo M, Sintonen H, Rautonen J, Kaitila I. Health-related quality of life of patients with genetic skeletal dysplasias. Eur J Pediatr. 1998;157:114-21.

2. Broderick JE, DeWitt EM, Rothrock N, Crane PK, Forrest CB. Advances in patient-reported outcomes: The NIH PROMIS ${ }^{\circledR}$ measures. EGEMS (Wash DC). 2013;1 (1):1015. https://doi.org/10.13063/2327-9214.1015.

3. Bullinger M, Quitmann J, Power M, Herdman M, Mimoun E, DeBusk K, et al. Assessing the quality of life of health-referred children and adolescents with short stature: development and psychometric testing of the QoLISSY instrument. Health Qual Life Outcomes. 2013;11:76.

4. Cella D, Riley W, Stone RN, Reeve B, Yount S, et al. The patient-reported outcomes measurement information system (PROMIS) developed and tested its first wave of adult self-reported health outcome item banks: 2005-2008. J Clin Epidemiol. 2010;63:1179-94.

5. Center for Devices and Radiological Health. Value and use of patient reported outcomes (PROs) in assessing effects of medical devices. CDRH Strategic Priorities 2016-2017. https://www.fda.gov/downloads/About FDA/CentersOffices/OfficeofMedicalProductsandTobacco/CDRH/CDRHV isionandMission/UCM588576.pdf. Accessed 14 April, 2020.

6. Cieza A, Oberhauser C, Bickenbach J, Chatterji S, Stucki G. Towards a minimal generic set of domains of functioning and health. BMC Publ Health. 2014;14:218.
7. Cieza A, Fayed N, Bickenbach J, Prodinger P. Refinements of the ICF linking rules to strengthen their potential for establishing comparability of health information. Disabil Rehabil. 2016;41:574-83.

8. Condon DM, Chapman R, Shaunfield S, Kallen MA, Beaumont JL, Eek D, et al. Does recall period matter? Comparing PROMIS ${ }^{\circledR}$ physical function with no recall, 24-hr recall, and 7-day recall. Qual Life Res. 2020;29:745-53.

9. Cook KF, Jensen SE, Schalet BE, Beaumont JL, Amtmann D, Czajkowski S, et al. PROMIS ${ }^{\circledR}$ measures of pain, fatigue, negative affect, physical function, and social function demonstrated clinical validity across a range of chronic conditions. J Clin Epidemiol. 2016;73:89-102.

10. Coulter, A. Measuring what matters to patients. BMJ. 2017;356:j816.

11. de Walt DA, Rothrock N, Yount S, Stone AA. Evaluation of item candidates: the PROMIS qualitative Item Review. Med Care. 2007:45(Suppl 1):12-21.

12. de Vet $\mathrm{H}$, Terwee $\mathrm{C}$, Mokkink L, Knol D. Measurement in medicine: a practical guide. Cambridge: University Press; 2011.

13. Finnish Institute for Health and Welfare. National FinSote Survey. 2016. https://thl.fi/en/web/thlfi-en/research-and-expertwork/population-studi es/national-finsote-survey. Accessed 14 April, 2020.

14. Fougeyrollas P, Noreau L, St Michel G, Boschen K. Measure of the quality of the environment. January 2008 ed. Québec: INDCP, 1999

15. Gollust SE, Thompson RE, Gooding HC, Biesecker BB. Living with achondroplasia in an average-sized world: an assessment of quality of life. Am J Med Genet A. 2003;120A:447-58.

16. Hiekkala S, Muñoz M, Tallqvist S, Anttila H, Pesola Kirsti, Leppäjoki S, et al. (2017) LYHTY: Lyhytkasvuisten toimintakyky ja haasteet esteettömyydessä ja yhdenvertaisuudessa [Functioning and challenges in accessibility and equality of short statured people]. THL Työpapereita 31, 2017. Juvenes Print - Suomen Yliopistopaino OY: Helsinki. http://urn.fi/URN:ISBN:978952-302-908-8. Accessed 14 April, 2020.

17. Hyvönen $H$, Anttila H, Tallqvist S, Muñoz M, Leppäjoki-Tiistola S, Teittinen A, Mäkitie $\mathrm{O}$, Hiekkala S, et al. Functioning and equality according to international classification of functioning, disability and health (ICF) in people with skeletal dysplasia compared to matched control subjects-a cross-sectional survey study. BMC Musculoskelet Disord. 2020;21:808.

18. Krüger L, Pohjolainen T, Kaitila I, Kautiainen H, Arkela-Kautiainen M, Hurri H. Health-related quality of life and socioeconomic situation among diastrophic dysplasia patients in Finland. J Rehabil Med. 2013;45:308-13.

19. Lorne H, Newman CJ, Unger S. Is height important for quality of life in children with skeletal dysplasias? Eur J Med Gen. 2020;63:103816.

20. Magasi S, Wong A, Gray DB, Hammel J, Baum C, Wang C-C, et al. Theoretical foundations for the measurement of environmental factors and their impact on participation among people with disabilities. Arch Phys Med Rehabil. 2015;96:569-77.

21. Maribo T, Petersen KS, Handberg C, Melchiorsen H, Momsen AM, Nielsen CV, et al. Systematic literature review on ICF from 2001 to 2013 in the Nordic countries focusing on clinical and rehabilitation context. J Clin Med Res. 2016;8(1):1-9.

22. Mason M. Sample size in PhD studies using qualitative interviews. Qual Soc Res. 2010;11:3.

23. Miles MB, Huberman AM. Qualitative data analysis. 2nd ed. California: Sage; 1994.

24. Mortier GR, Cohn DH, Cormier-Daire V, Hall C, Krakow D, Mundlos S, et al. Nosology and classification of genetic skeletal disorders: 2019 revision. Am J Med Genet A. 2019;179:2393-419.

25. Northwestern University. In: PROMIS ${ }^{\circledR}$ instrument development and validation scientific standards version 2.0. 2013. http://www.healthmeas ures.net/images/PROMIS/PROMISStandards_Vers2.0_Final.pdf. Accessed 14 April, 2020.

26. Prodinger B, Cieza A, Oberhauser C, Bickenbach J, Ustun TB, Chatterji S, et al. Toward the international classification of functioning, disability and health (ICF) rehabilitation set: a minimal generic set of domains for rehabilitation as a health strategy. Arch Phys Med Rehabil. 2016;97:875-84.

27. Rauch A, Cieza A, Stucki G. How to apply the international classification of functioning, disability and health (ICF) for rehabilitation management in clinical practice. Eur J Phys Rehabil Med. 2008:44:329-42.

28. Rauch A, Lückenkemper M, Cieza A. Introduction to the international classification of functioning, disability and health. In: Bickenbach JE, Cieza A, Rauch A, Stucki G, editors. ICF core sets: manual for clinical practice. Göttingen: Hogrefe Publishing; 2012. 
29. Reinhardt JD, Miller J, Stucki G, Sykes C, Gray DB. Measuring impact of environmental factors on human functioning and disability: a review of various scientific approaches. Disabil Rehabil. 2011;33:22-3.

30. Rose M, Bjorner JB, Gandek B, Bruce B, Fries JF, Ware JE Jr. The PROMIS physical function item bank was calibrated to a standardized metric and shown to improve measurement efficiency. J Clin Epidemiol. 2014;67:516-26.

31. Scheuringer M, Stucki G, Huber EO, Brach M, Schwarzkopf SR, Kostanjsek $\mathrm{N}$, et al. ICF core set for patients with musculoskeletal conditions in early post-acute rehabilitation facilities. Disabil Rehabil. 2005;27:405-10.

32. Selb M, Escorpizo R, Kostanjsek N, Stucki G, Ustun B, Cieza A. A guide on how to develop an international classification of functioning, disability and health core set. Eur J Phys Rehabil Med. 2015;51:105-17.

33. Stucki G, Brodinger B, Bickenbach J. Four steps to follow when documenting functioning with the international classification of functioning, disability and health. Eur J Phys Rehabil Med. 2017;53:144-9.

34. Stucki G, Grimby G. Development of ICF core sets for chronic conditions. J Rehab Med. 2004:36(Suppl 44):5-141.

35. Thompson S, Shakespeare T, Wright MJ. Medical and social aspects of the life course for adults with a skeletal dysplasia: a re-view of current knowledge. Disabil Rehabil. 2008;30:1-12.

36. Tallqvist $\mathrm{S}$, Anttila $\mathrm{H}$, Kallinen $\mathrm{M}$, et al. Health, functioning and accessibility among spinal cord injury population in Finland: protocol for the FinSCl study. J Rehabil Med. 2019;51:273-80.

37. Terwee CB, Prinsen CAC, Chiarotto A, Westerman MJ, Patrick DL, Alonso J, et al. COSMIN methodology for evaluating the content validity of patient-reported outcome measures: a Delphi study. Qual Life Res. 2018;27:1159-70.

38. Tucker CA, Cieza A, Riley AW, et al. Concept analysis of the patient reported outcomes measurement information system $\left(\mathrm{PROMIS}{ }^{\circledR}\right)$ and the international classification of functioning, disability and health (ICF). Qual Life Res. 2014;23:1677-86.

39. Tucker CA, Escorpizo R, Cieza A, et al. Mapping the content of the patientreported outcomes measurement information system $\left(\mathrm{PROMIS}^{\circledR}\right)$ using the international classification of functioning. Health Disabil Qual Life Res. 2014;23:2431-8.

40. Tuomi J, Sarajärvi A. Laadullinen tutkimus ja sisällönanalyysi [Qualitative research and content analysis]. Vantaa: Kustannusosakeyhtiö Tammi; 2013.

41. United Nations. Convention on the Rights of Persons with Disabilities and Optional Protocol. 2006. http://www.un.org/disabilities/documents/ convention/convoptprot-e.pdf. Accessed 14 April, 2020.

42. Vaara P, Sintonen H, Peltonen J, Hokkanen H, Poussa M, Ryoppy S. Healthrelated quality of life in patients with diastrophic dysplasia. Scand J Publ Health. 1999;27:38-42.

43. Wikström M, Anttila H, Savinainen M, Kouvonen A, Joensuu M. Development and content validity of the Abilitator: a self-report questionnaire on work ability and functioning aimed at the population in a weak labour market position. BMC Publ Health. 2020;20:327.

44. Whiteneck GG, Harrison-Felix CL, Mellick DC, Charlifue SB, Gerhart KA Quantifying environmental factors: A measure of physical, attitudinal, service, productivity, and policy barriers. Arch Phys Med Rehabil. 2004;85:1324-35

45. World Health Organisation. Chapter V. Supplementary section for functioning. In: International Classification of Diseases - Mortality and Morbidity Statistics. 2020. https://icd.who.int/dev11/I-m/en. Accessed 14 April, 2020

46. World Health Organization. International classification of functioning, disability and health: ICF. Geneva: World Health Organization; 2001.

47. World Health Organization (2016) International Statistical Classification of Diseases and Related Health Problems 10th Revision. https://icd.who.int/ browse10/2016/en. Accessed 14 April, 2020.

\section{Publisher's Note}

Springer Nature remains neutral with regard to jurisdictional claims in published maps and institutional affiliations.
Ready to submit your research? Choose BMC and benefit from:

- fast, convenient online submission

- thorough peer review by experienced researchers in your field

- rapid publication on acceptance

- support for research data, including large and complex data types

- gold Open Access which fosters wider collaboration and increased citations

- maximum visibility for your research: over 100M website views per year

At BMC, research is always in progress.

Learn more biomedcentral.com/submissions 